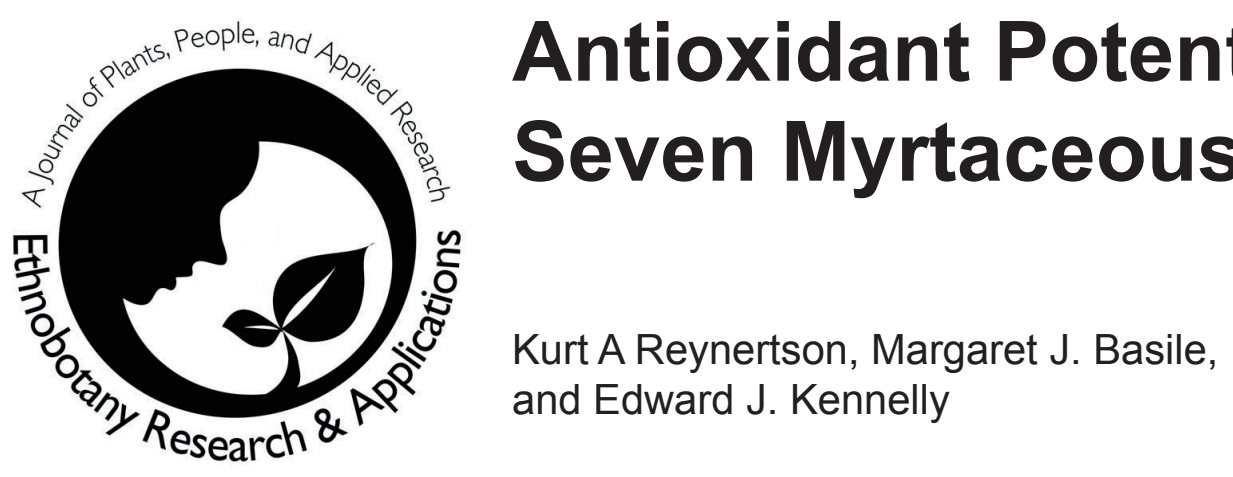

\begin{abstract}
Many fruits of the Myrtaceae have a rich history of use both as edibles and as traditional medicines in divergent ethnobotanical practices throughout the tropical and subtropical world. From South America to Southeast Asia, these fruits have been used for a wide variety of ailments, including cough, diabetes, dysentery, inflammation and ringworm. These same fruits are also used to make many food products. Based on information regarding ethnomedical use, known phytochemistry, fruit color, popularity as edibles and availability, the fruits of several edible species from the subtribe Eugeniinae have been selected for phytochemical analysis in an attempt to discover new antioxidants. The fruits of six species in this group have shown a strong antioxidant activity in the 1,1-diphenyl-2-picrylhydrazyl chemical assay. The UV absorbance spectrum of the most active compound in Eugenia uniflora L. indicates that it is a flavonoid. Polyphenolic compounds like flavonoids have an enormous range of biological activity and are known to inhibit oxidative damage in vivo better than the classical vitamin antioxidants. In plants, they protect against lipid peroxidation and UV damage that can affect tropical fruits growing under severe conditions including high heat and intense sunlight.
\end{abstract}

\title{
Introduction
}

In an initial screening of over thirty edible tropical fruits, extracts of Eugenia uniflora L. (Myrtaceae) proved to be highly active in the 1,1-diphenyl-2-picrylhydrazyl (DPPH) antioxidant assay, and polyphenolic compounds are implicated in this activity. A literature search of the plants most closely allied to E. uniflora was therefore conducted based on the hypothesis that allied species may contain similar antioxidant compounds. The ethnomedical and ethnobotanical uses of these plants was correlated with known phytochemical data to ascertain a list of promising species for further research to find new potent antioxi-

dant fruits and compounds. Increasing understanding of the role oxidative stress plays in disease has made the search for antioxidants more important.

\section{Antioxidants and Disease}

Oxidative damage in the human body plays an important causative role in disease initiation and progression (Yamaguchi et al. 1998). Oxidation of low-density lipoprotein (LDL) is a major factor in the promotion of heart disease and atherosclerosis (Frankel et al. 1993a, Jacob \& Burri 1996, Steinberg 1997). Damaging free radicals and reactive oxygen species (ROS) are produced naturally through oxidative metabolism and have also been linked to some cancers (Frankel et al. 1993a, Jacob \& Burri 1996). Damage is generally reduced by endogenous antioxidants, but additional protection is necessary, and nutritive elements from food are critical in disease prevention. Repeated damage caused by ROS throughout the span of a human life increases with time, and is a major cause of age-related cancers and other oxidativelyinduced diseases.

\section{Correspondence}

Kurt A. Reynertson and Edward J. Kennelly, The Graduate Center, City University of New York and Lehman College, Department of Biology, 250 Bedford Park Boulevard West, Bronx, NY 10468. U.S.A. allerslev@gmail. com, Edward.Kennelly@lehman.cuny.edu

Margaret J. Basile, University of Miami School of Medicine, Department of Neurology, 1501 NW 9th Avenue, Miami, FL 33136. U.S.A.

Ethnobotany Research \& Applications 3:025-035 (2005) 
Diets high in fruits and vegetables and low in cholesterol and fats are inversely correlated with the incidence of coronary heart disease (CHD) and cancer (Hertog et al. 1993, Hertog et al. 1995, Knekt et al. 1996, Ness \& Powles 1999, Pietta 2000, van Poppel et al. 1994). Natural antioxidants from fruits and vegetables provide a measure of protection that slows the process of oxidative damage, and are implicated as the protective constituents of these foods (Hertog et al. 1993, Hollman \& Katan 1999, van Poppel et al. 1994). Research in natural antioxidants is becoming increasingly important both in understanding the beneficial aspects of plant foods and in improving the quality of fatty foods. Antioxidants are routinely used by the industry to prevent the oxidation of food in storage and inhibit rancidity. The well-known vitamin antioxidants in food include ascorbic acid, b-carotene and a-tocopherol. Many clinical and epidemiological studies have sought to demonstrate the efficacy of these vitamins in preventing a wide variety of diseases (Blumenthal et al. 2000, Giugliano 2000, Haegele et al. 2000, Jacob \& Burri 1996, Pellegrini et al. 2000, Scheen 2000). However, some of these studies failed to show significant antioxidative protection in vitro (Pellegrini et al. 2000, Scheen 2000), which suggests that vitamins obtained via whole food or by a balanced diet may be more effective than supplements, possibly through synergistic interactions with other compounds.

\section{Polyphenolic Antioxidants}

Recent studies have shown that many flavonoids and related polyphenols are actually better antioxidants than vitamins (Frankel et al. 1993b, Pietta 2000, Vinson et al. 1999a). Fruits and vegetables are high in flavonoid content; flavonoids impart color and taste to flowers and fruits, and it is estimated that humans consume between a few hundred milligrams and one gram of flavonoids every day (Hollman \& Katan 1999, Pietta 2000). Flavonoids appear in blood plasma at pharmacologically active levels after eating flavonoid-rich foods but do not accumulate in the body (Cao et al. 1998, Hollman \& Katan 1999). Consuming flavonoids regularly increases longevity by reducing inflammation and contributing to the amelioration of atherosclerosis from CHD (Frankel et al. 1993a). The range of flavonoid biological activity is large; in addition to scavenging free radicals and ROS, flavonoid actions include anti-inflammatory, antiallergenic, antiviral, antibacterial, antifungal, antitumor, and antihemorrhagic (Formica \& Regelson 1995, Slowing et al. 1996). Flavonoids also inhibit a number of enzymes, including aldose reductase, a-glucosidase, xanthine oxidase, monooxygenase, lipoxegenase and cyclooxygenase (Middleton \& Kandaswami 1993, Yoshikawa et al. 1998). Plant polyphenols interact with LDL, enriching and protecting it from oxidation when entering the bloodstream. The so-called "French Paradox" refers to the fact that despite the high fat content of the French diet, there is a lower incidence of CHD in France than in countries where fat intake is similar. This has been attributed to the high polyphenolic content of red wine and other fruits and vegetables (Burns et al. 2000, Frankel et al. 1993a).

There are over 4000 naturally occurring flavonoids in several subclasses. All have the same basic C6-C3-C6 phenolic carbon skeleton (Figure 1). Flavonoids are ubiquitous in the higher plants and play an ecological as well as physiological role. The anthocyanins are the most important flower and fruit pigments; they attract pollinators and seed dispersers and protect plant tissues from ultraviolet (UV) radiation damage. Some flavonoids act as antifeedants to herbivorous pests. The isoflavones are responsible for the chemical signaling involved in legumous root node formation (Dewick 1997, Harborne \& Baxter 1999, Robinson 1991).

Figure 1. Basic structures of $\mathbf{A}$ a flavonoid and $\mathbf{B}$ an anthocyanidin.

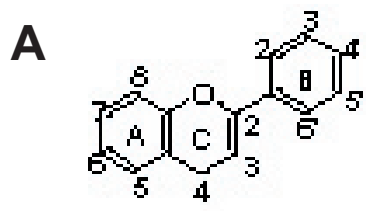

B

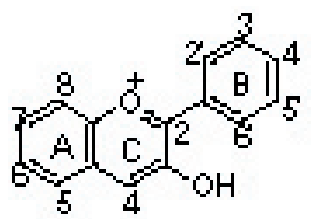

Studies suggest that the antioxidant potential of phenolics is mainly due to their ability to act as reducing agents (Burns et al. 2000, Kähkönen et al. 1999, Vinson et al. $1999 b)$. It is well established that the efficacy of flavonoids as antioxidants stems from the number and position of the hydroxyl substitutions on the basic structure; an increase in number of hydroxyl groups is directly correlated with increasing activity, and the 3',4' -dihydroxy substitution is significant (Cao et al. 1997, Rice-Evans et al. 1996, RiceEvans et al. 1997).

Anthocyanins (Figure 1B) are the glycosides of anthocyanidins, and contribute greatly to the antioxidant properties of certain fruits. As pigments, they produce the orange, red and blue colors in fruits and flowers. The antioxidant anthocyanidin that colors blueberries and grapes bluish-red is delphinidin. Other known antioxidant anthocyanins include cyanidin (orange-red), pelargonidin (orange), malvidin (bluish-red) and peonidin (red) (Wang et al. 1997). Fruit color is therefore an important indicator of possible polyphenolic compounds. 


\section{Chemotaxonomic Approach to Antioxidant Discovery}

As early as 1897, Baker and Smith investigated the essential oils of Eucalyptus (Myrtaceae) and found a close connection between the chemistry of the oils and the taxonomy of the plants (Gibbs 1993). It has since been established that chemistry is very useful in plant systematics. Likewise, systematics can be used in the search for bioactive compounds, and flavonoids are considered excellent taxonomic guides (Bate-Smith 1963). While flavonoids are ubiquitous in the higher plants, certain subclasses of flavonoids can be taxa-specific. It is unusual for rare flavonoids to occur outside a group in which they have been discovered. Glycosidic combinations are proving to be highly specific within families, and some morphological characteristics can be linked to particular flavonoid patterns (Harborne 1963). Some methylation patterns occur only in certain families (Pierpoint 1986). Anthocyanins can occur in any part of a plant, and different parts of the same plant often have different anthocyanin pigments. The glycosylation pattern is often consistent in a plant, and correlates with systematic information (Harborne 1963). Harborne found that species which do not conform to genera glycosidic patterns are exceptional in other respects as well. Leaves and fruits tend to have simpler pigments than flowers, and there is an evolutionary trend toward more complex anthocyanin structures (Harborne 1963). Complex pigments with several glycosylations are more stable to light degradation and enzymatic attack. The evolutionary trend towards complexity is paralleled by a trend toward the blue color, which in flowers is related to the color preference of insect pollinators.

Anthocyanin content of fruits tends to increase as the fruit matures, becoming complexed with metals and other flavonoids (Pierpoint 1986, Silva 1997). The most common anthocyanidin is cyanidin, which occurs in $80 \%$ of permanently pigmented leaves, $69 \%$ of fruits and $50 \%$ of flowers. The next two most common anthocyanidins are delphinidin and pelargonidin. Delphinidin is wholly absent from some families, and abundant in others. As of 1995, only about 1000 species had been examined for anthocyanins, and only about one-fifth of those species have had the sugar groups fully described. This represents a tiny fraction of the 250,000 known species of angiosperm. Harborne believes that there must be a considerable number of new anthocyanin structures yet to be discovered (Harborne 1963, Pierpoint 1986).

The chemotaxonomic approach to antioxidant discovery includes reviewing species that have been phytochemically examined. Information can be extrapolated to allied plants. Species closely related to plants containing known polyphenolic antioxidants are likely to have similar polyphenolic constituents. Therefore, the phytochemistry of one plant may be used as a clue for a related plant. The hypothesis is that antioxidant activity may "run in the family."

\section{Plant Selection and Collection}

Ethnobotanists regularly structure questionnaires to probe indigenous knowledge for the medicinal uses of plants. Most indigenous knowledge does not include a list of plants that help scavenge free radicals. Researchers looking for new antioxidants can, however, use ethnomedicinal information as a guide, paying special attention to plants that are used for illnesses or conditions that are ameliorated by compounds also linked to antioxidant activity. Polyphenolics are diverse in their biological activities, so ethnomedical information that hints at polyphenolic content could point to possible antioxidants.

For this study, the plants closely allied to $E$. uniflora were reviewed for ethnobotanical and phytochemical data. Several databases were queried, including NAPRALERT, Chemical Abstracts and Biological Abstracts. The number of NAPRALERT hits for each species studied is given in Table1. Some of the species queried had little or no phytochemical or ethnobotanical data. Those that are widely used as food or medicine have often been phytochemically examined.

Several species were selected, and seven have been collected and tested: Eugenia aggregata (Velloso) Kiaersk., E. foetida Pers., E. stipitata McVaugh, E. uniflora, Myrciaria cauliflora (Mart.) O. Berg, Syzygium jambos (L.) Alston and S. samarangense (Blume) Merr. \& L.M. Perry). Several other species have also been marked for testing, and analysis will be undertaken when fruits ripen. All are closely related species of the Myrtaceae subtribe Eugeniinae, and most are cultivated for their edible fruits. Some of these species are also used medicinally, although thorough phytochemical studies have not been done for each. Table 1 summarizes the known phytochemistry and ethnobotany of the fruits.

Several institutions in southern Florida dedicated to the propagation of tropical fruits generously permitted us to collect fruit. Collecting within the United States eliminates the need for international collection permits, and these institutions represent collections of plants that have been pre-selected and imported as edibles, medicinals or both. Fruit was collected from The Kampong (The National Tropical Botanical Gardens), The Broward County Rare Fruit and Vegetable Council Experimental Plot, the Fruit and Spice Park and The University of Florida Tropical Resource and Education Center. Fruits were shipped frozen to the laboratory, where they were kept at $-20^{\circ} \mathrm{C}$ until extraction. Voucher specimens have been deposited in the New York Botanical Garden herbarium.

\section{The Myrtle Family}

The Myrtaceae is a well defined family, with leathery glandular leaves containing viscous aromatic terpenoid and 
Table 1. Ethnobotanical and phytochemical information of Eugeniioid fruits. Total number of NAPRALERT hits is given, along with antioxidant activity expressed as a DPPH IC50. A lower IC50 value indicates greater activity. Known vitamin antioxidants ascorbic acid and a-tocopherol have IC50 values of $18.3 \mathrm{mg} / \mathrm{mL}$ and $53.3 \mathrm{mg} / \mathrm{mL}$, respectively.

\begin{tabular}{|c|c|c|c|c|c|c|}
\hline Species & $\begin{array}{l}\text { Vernacular } \\
\text { Name }\end{array}$ & \begin{tabular}{|l|} 
Fruit \\
Color
\end{tabular} & Ethnobotanical Information & \begin{tabular}{|l|} 
Previous \\
Phytochemical Work
\end{tabular} & Total & \begin{tabular}{|l} 
DPPH \\
IC50 \\
$(\mathrm{mg} / \mathrm{mL})$
\end{tabular} \\
\hline \begin{tabular}{|l} 
Eugenia \\
aggregata
\end{tabular} & $\begin{array}{l}\text { Rio Grande } \\
\text { cherry }\end{array}$ & $\begin{array}{l}\text { Reddish- } \\
\text { purple }\end{array}$ & $\begin{array}{l}\text { Brazil: eaten fresh, used } \\
\text { for jams and jellies } 1\end{array}$ & $\begin{array}{l}\text { Catechin and } \\
\text { epicatechin } 2\end{array}$ & 0 & 74.1 \\
\hline $\begin{array}{l}\text { Eugenia } \\
\text { foetida }\end{array}$ & $\begin{array}{l}\text { Topiary } \\
\text { bush }\end{array}$ & Purple & Hedge, topiary & & 0 & $15.9^{*}$ \\
\hline $\begin{array}{l}\text { Eugenia } \\
\text { stipitata }\end{array}$ & Araca-boi & Yellow & Desserts $^{7}$ & $\begin{array}{l}\text { Terpenes, primarily } \\
\text { sesquiterpenes }^{3}\end{array}$ & 0 & 79.0 \\
\hline $\begin{array}{l}\text { Eugenia } \\
\text { uniflora }\end{array}$ & $\begin{array}{l}\text { Surinam } \\
\text { cherry }\end{array}$ & \begin{tabular}{|l|} 
Red to \\
purple to \\
black
\end{tabular} & $\begin{array}{l}\text { Brazil: eaten fresh, used for } \\
\text { desserts, liqueurs, wines } \\
\text { (syrups and wines used } \\
\text { medicinally); } 4 \text { astringent, } \\
\text { high blood pressure }\end{array}$ & $\begin{array}{l}\text { Ascorbic acid, b- } \\
\text { carotene, and a few } \\
\text { sesquiterpenes } 6\end{array}$ & 235 & 19.6 \\
\hline $\begin{array}{l}\text { Myrciaria } \\
\text { cauliflora }\end{array}$ & Jaboticaba & $\begin{array}{l}\text { Dark red } \\
\text { to purple- } \\
\text { black }\end{array}$ & $\begin{array}{l}\text { Brazil: eaten fresh, used for } \\
\text { jam, tarts, strong wine and } \\
\text { liqueur, as a treatment for } \\
\text { hemoptysis, asthma, diarrhea } \\
\text { dysentery and chronic } \\
\text { inflammation of the tonsils. }^{7}\end{array}$ & Tannins $^{7}$ & 0 & 35 \\
\hline $\begin{array}{l}\text { Syzygium } \\
\text { jambos }\end{array}$ & Rose apple & $\begin{array}{l}\text { Yellow } \\
\text { with slight } \\
\text { blush }\end{array}$ & $\begin{array}{l}\text { India: tonic for the brain and } \\
\text { for liver problems, as an } \\
\text { astringent, and digestive, }{ }^{8} \\
\text { distilled to make rosewater. }^{7}\end{array}$ & Terpenoids & 282 & 247 \\
\hline \begin{tabular}{|l|} 
Syzygium \\
samarangense
\end{tabular} & Wax jambu & $\begin{array}{l}\text { Pink to } \\
\text { red }\end{array}$ & $\begin{array}{l}\text { India: eaten fresh; } 9 \\
\text { Malaya: greenish fruits } \\
\text { are eaten raw with salt or } \\
\text { cooked as a sauce } 7\end{array}$ & $\begin{array}{l}\text { Two flavonol } \\
\text { glycosides as well as } \\
\text { epigallocatechin 3-O- } \\
\text { gallate, epicatechin } \\
\text { 3-O-gallate, and } \\
\text { samarangenin } \\
\text { A and B. } 10\end{array}$ & 61 & 76.8 \\
\hline
\end{tabular}

polyphenolic substances and flowers with numerous stamens (Landrum 1988). The family is divided into two subfamilies, the Leptospermoidieae and Myrtoideae. Edible fruits and useful spices, including guava, pitanga, clove and bay rum are produced by the closely related genera of the Myrtoideae, which can be divided into three subtribes. The subtribe Eugeniinae represents a large and morphologically diverse group, and most of these species have at one time been assigned to the genus Eugenia. Splitting the group depends on deciding which species to remove from Eugenia (McVaugh 1966), and the full taxonomic arrangement is still under debate (Mabberley 1993). They are pantropical in occurrence, concentrating in South America and Southeast Asia-Eastern Australia. The genus Eugenia is now mostly considered the neotropical group, numbering around 1000 species, and the plants designated Syzygium are generally considered by many to be the Old World genus. Other genera in this subtribe include Myrciaria, Plinia, Catinga and Calycorectes. Researchers disagree on the exact taxonomic arrangement, and many of these plants have multiple synonyms in at least one of these genera (Facciola 1998, McVaugh 1966, Popenoe 1920).

The fruits of this subtribe are often described by their bright anthocyanin colors, including orange, red, purple and black (dark purple). Examples of fruits in the subtribe are shown in Figure 2. They are sweet to tart, aromatic and many are astringent, indicating the presence of tannins. The taste is often described as somewhat acid. New shoot growth for many species is wine-colored (Facciola 1998, Popenoe 


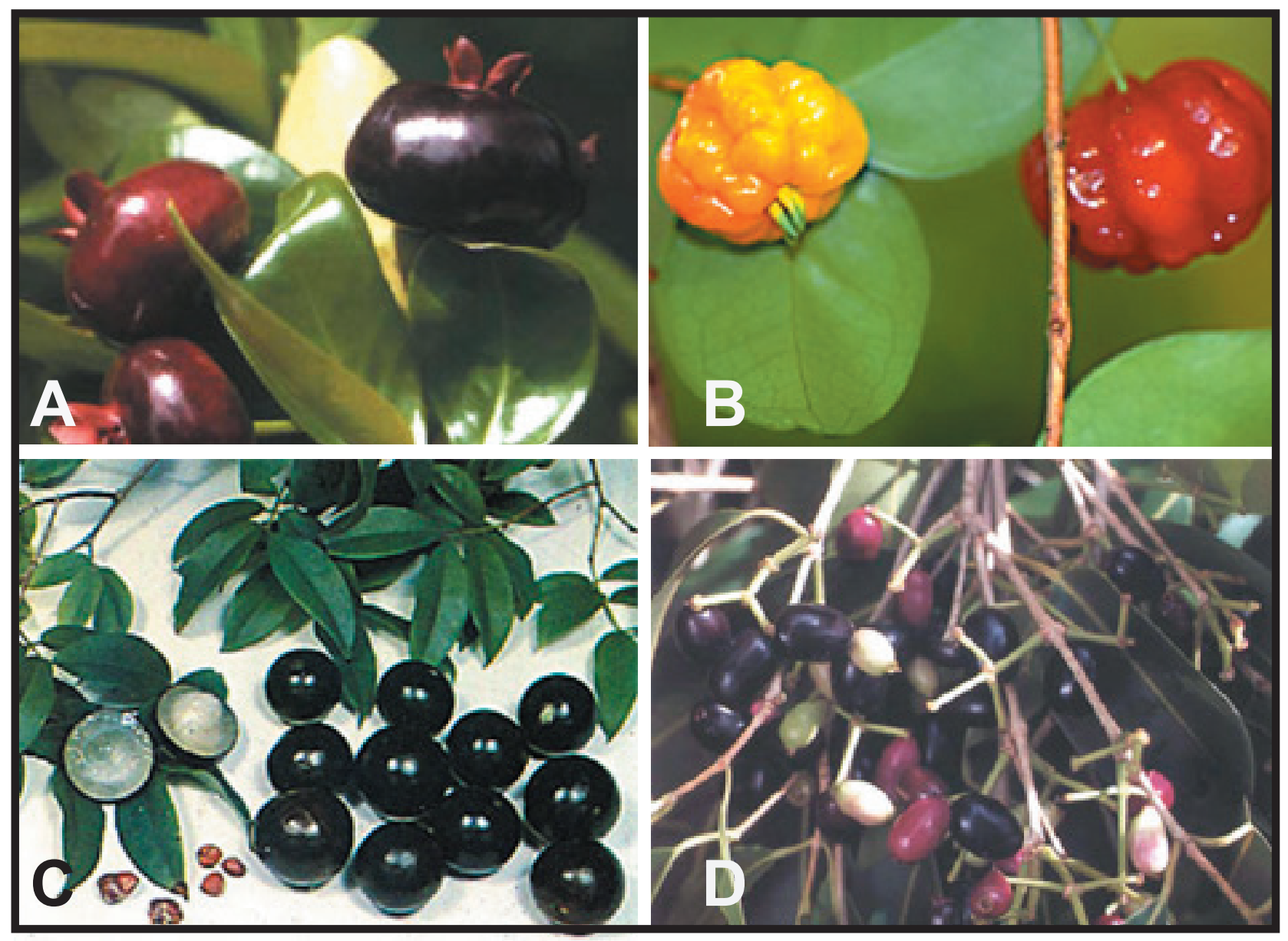

Figure 2. Examples of fruits in Myrtaceae subtribe Eugeniinae. A. Eugenia brasiliensis, B. Eugenia uniflora, C. Myrciaria cauliflora, D. Syzygium cumini.

1920), suggesting a high anthocyanin content. Many known antioxidant flavonoids have been isolated from all parts of many species in this group. Haron et al. found that flavonoid composition of New World and Old World Eugenia species is similar (Haron et al. 1992). Seventeen Eugenia species were tested, and myricetin was present in leaf extracts of $100 \%$, quercetin in $71 \%$, and kaempferol in $24 \%$. Ellagic acid, procyanidin and prodelphinidin were found in most species tested, and Nair and Subramanian (Nair and Subramanian 1962) found that ellagic acid and myricetin are common throughout the family, as is methylellagic acid (Hegnauer 1990). In dicots, ellagic acid is usually confined to certain families and plants containing trihydroxy flavonoids, just as caffeic and p-coumeric acids are found along with corresponding di- and monohydroxy flavonoids (Bate-Smith 1963). Theoduloz showed that flavonoids in the five species of the Myrtaceae tested inhibit xanthine oxidase activity (Theoduloz et al. 1988), Schmeda-Hirschman credits this activity to the presence of the flavonoids quercitrin, quercetin, myricitrin, and myricetin (Schmeda-Hirschmann et al. 1987). High doses of the leaves showed no toxicity.
Surinam cherry ( $E$. uniflora) is widely regarded as one of the best tasting of the Eugenia species, and the fruits average about 1 inch in size. They have a characteristic ribbed appearance, and several cultivars have been developed with fruits ranging from orange to crimson to black (Facciola 1998, Morton 1987). There is an extensive amount of literature documenting the ethnomedical uses of the leaves of Surinam cherry (Consolini et al. 1999, Duke 2000, Rücker et al. 1977, Schapoval et al. 1994, Schmeda-Hirschmann et al. 1987, Weyerstahl et al. 1988), and most of the phytochemical work has subsequently focused on characterizing the essential oil of the leaves (Weyerstahl et al. 1988). Ascorbic acid, b-carotene, and a few sesquiterpenes have been identified from the fruits (Duke 2000, Rücker et al. 1977), but no studies of flavonoid content of the fruit have been done. Several well-known antioxidant flavonoids have been reported from leaf extracts, including myricetin, myricitrin, gallocatechin, quercetin, and quercitrin (Schmeda-Hirschmann et al. 1987) as well as the tannins eugeniflorin D-1 and D-2 (Lee et al. 1997). Popenoe notes that the Brazilians prepare a liqueur from the fruits, and consider syrups and wines to have a medicinal value (Popenoe 1920). In Ma- 
deira, fruits of $E$. uniflora are eaten for intestinal troubles (Rivera \& Obón 1995). Fruits and leaves are also used for their astringent qualities, and are active against high blood pressure (Bandoni et al. 1972). Water decoctions of $E$. uniflora leaves are used in Paraguay to lower cholesterol and blood pressure (Ferro et al. 1988), and have a highly significant anti-inflammatory action (Schapoval, et al. 1994). Ferro showed that leaf extracts were slightly active on lipid metabolism, and may exert a protective effect on triglycerides and very low-density lipoprotein levels (Ferro et al. 1988).

Other fruits in this subtribe are also colorful, with an extensive ethnobotanical and ethnomedical use that suggests a possible flavonoid content. $S$. jambos fruit is used as a tonic for the brain and for liver problems, as an astringent, and digestive and diuretic (Kirtikar \& Basu 1988, Morton 1987). The leaves contain seventeen different flavonoids (Constant et al. 1997, Slowing, et al. 1996, Slowing et al. 1994) and are used as an anesthetic, anti-inflammatory, and astringent, for apoplexy, asthma, bronchitis, cough, diabetes, dysentery, influenza, and rheumatism (Rivera \& Obón 1995). S. samarangense, which is cultivated in India for its edible fruit (Anonymous 1952) contains two flavonol glycosides as well as epigallocatechin 3-O-gallate, epicatechin 3-O-gallate, and samarangenin A and B (Harborne and Baxter 1999). In Taiwan, the flowers, which contain tannins, are used to treat fever and halt diarrhea. Flowers also contain desmethoxymatteucinol, 5-O-methyl-4'-desmethoxymatteucinol, oleanic acid and b-sitosterol (Morton 1987). The jaboticaba (Myrciaria cauliflora) is a popular edible in Brazil, much like grapes in the U.S. (Popenoe 1920). They are a dark red to maroon-purple and black, and are used to make jam, tarts, strong wine and a liqueur (Facciola 1998). E. aggregata is a popular reddish-purple edible in Brazil, eaten fresh or used to make jams and jellies (Facciola 1998) which has not been phytochemically examined. In preparing this study, the phytochemistry and ethnobotany of each plant was reviewed and noted, but those uses and compounds associated with the fruit only were given more emphasis, and are summarized in Table 1.

\section{Laboratory Work}

In the current study, fruits were homogenized in a blender with methanol and extracted for one to two hours. Methanolic extracts were concentrated in vacuo and partitioned using a solvent-solvent procedure depicted in Figure 3. Hexane extracts contain lipid-soluble antioxidant vitamins such as b-carotene and a-tocopherol. Aqueous extracts contain sugars and ascorbic acid. The EtOAc fraction, being moderately polar, contains the polyphenolic components.

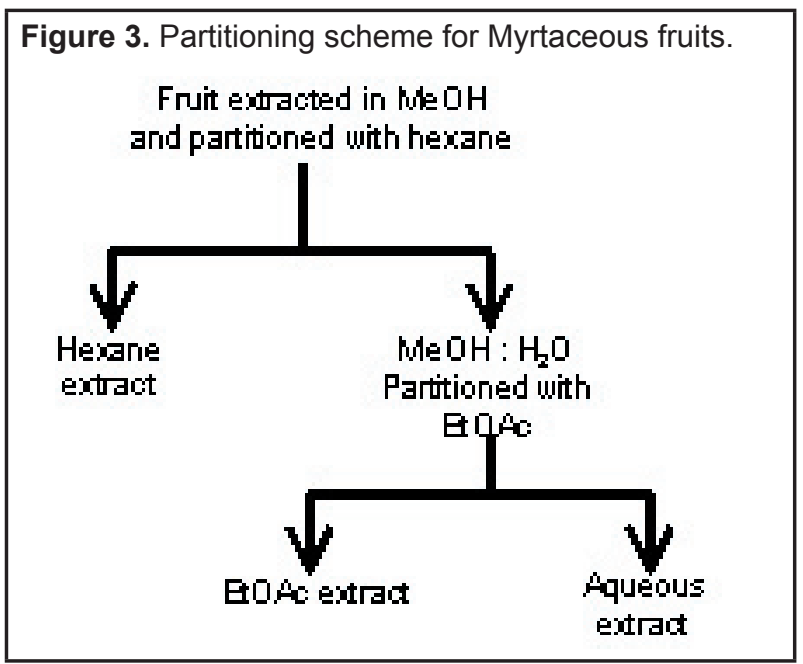

EtOAc fractions were tested in a simple DPPH chemical assay following Yamaguchi (Yamaguchi et al. 1998). DPPH (Figure 4) produces a stable free radical, and is a good indicator of radical scavenging capacity. The 50\% inhibition concentration (IC50) value is obtained using serial dilutions. A lower IC50 value indicates greater activity. An IC50 less than $50 \mu \mathrm{g} / \mathrm{mL}$ is considered very active, 50 -100 is moderately active, $100-200$ is slightly active and a value above $200 \mu \mathrm{g} / \mathrm{mL}$ is considered inactive. Ascorbic acid and a-tocopherol are used as positive controls, with IC50 values of $18.3 \mu \mathrm{g} / \mathrm{mL}$ and $53.3 \mu \mathrm{g} / \mathrm{mL}$, respectively.

The EtOAc fraction of $E$. uniflora was separated by vacuum-liquid chromatography and the most active fraction (SC_10) was analyzed by high performance liquid chromatography (HPLC) using an on-line DPPH assay developed by Koleva (Koleva et al. 2000) and adopted in our laboratory (Figure 5). This assay demonstrates the antioxidant activity of individual phytochemicals. Spec-

Figure 4. Stable free radical, of DPPH that is a good indicator of radical scavenging capacity.<smiles>O=[N+]([O-])c1cc([N+](=O)[O-])c(NN(c2ccccc2)c2ccccc2)c([N+](=O)[O-])c1</smiles> 


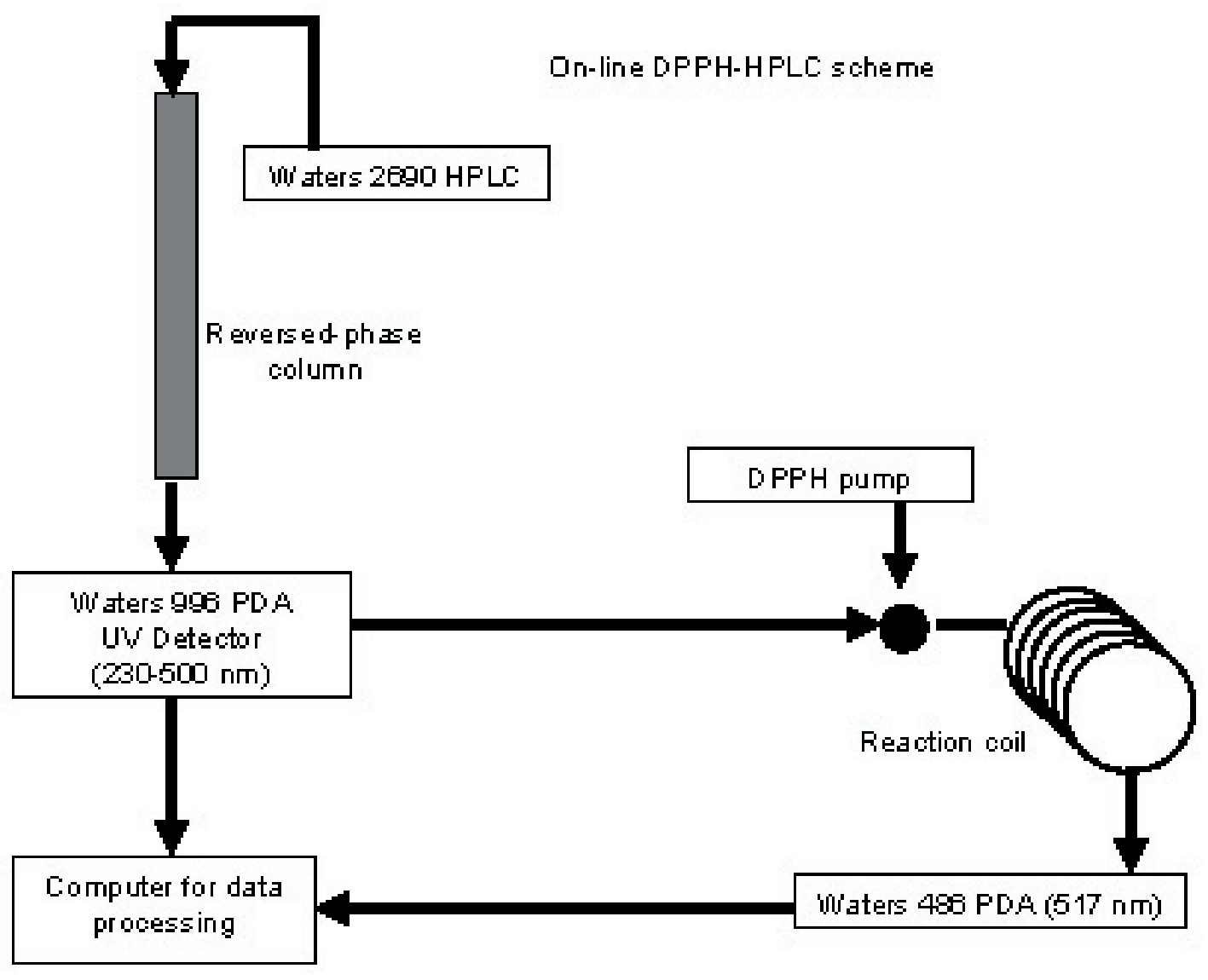

Figure 5. On-line Dpph-HPLC scheme.

tral data is collected both at $517 \mathrm{~nm}$ (for DPPH activity) and $230-500 \mathrm{~nm}$ (for flavonoid detection). After reacting, the radical absorbing activity is depicted on the chromatogram as a negative peak. As seen in Figure 6, the detection of compounds is graphically correlated to the activity in the assay. The main constituent eluted at 11.9 minutes and was very active in the assay as can be seen from the negative peak. The identity of this compound remains to be determined. Based on its UV absorbance profile it is very likely a flavonoid. The profile (Figure 6 , Inset A) is very similar to quercitrin, which has been isolated from leaf extracts of $E$. uniflora.

\section{Conclusions and Discussion}

Renowned pantropically as both food and medicine, these fruits have long been incorporated into traditional holistic health systems. Western medicine has, for the most part, overlooked them as potentially beneficial dietary components. Most of the pharmacological studies have not focused on the fruits. This study demonstrates that there are antioxidant compounds in these fruits. The most active fruits in the DPPH assay are E. foetida $(15.9 \mu \mathrm{g} / \mathrm{mL})$ and E. uniflora $(19.6 \mu \mathrm{g} / \mathrm{mL})$. M. cauliflora was also very active at $35 \mu \mathrm{g} / \mathrm{mL}$. E. aggregata, E. stipitata and S. samarangense were moderately active, with IC50 values of 74.1 $\mu \mathrm{g} / \mathrm{mL}, 79.0 \mu \mathrm{g} / \mathrm{mL}$ and $76.8 \mu \mathrm{g} / \mathrm{mL}$, respectively. Only $S$. jambos appears to be inactive at $247 \mu \mathrm{g} / \mathrm{mL}$. These fruits compare favorably with known antioxidants ascorbic acid $(18.3 \mu \mathrm{g} / \mathrm{mL})$ and a-tocopherol $(53.3 \mu \mathrm{g} / \mathrm{mL})$. Table $1 \mathrm{sum}$ marizes the DPPH assay results. Further understanding of the polyphenolic content of these fruits may be of great benefit in understanding the health aspects of both the traditional and modern uses of these fruits.

\section{Future Work}

Active compounds from these species will be isolated and analyzed to determine chemical identity. Novel compounds will be elucidated using modern well-established analytical methods. Finally, the antioxidant capacity of beverages, vinegars and jams made from the most active fruits will be tested to see if the antioxidant compounds remained intact during the juicing and fermenting process. 


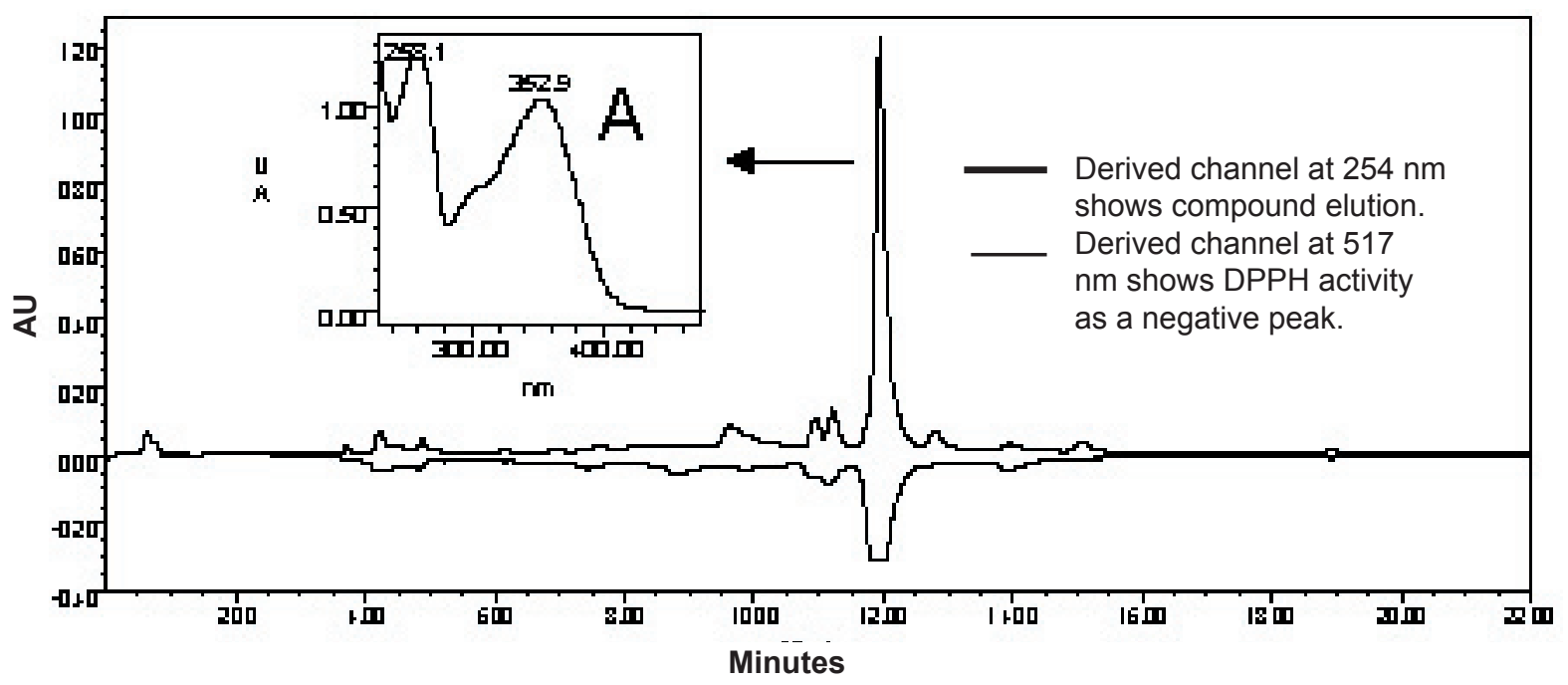

Figure 5. Chromatogram of VLC fraction SC_10 showing several active compounds in the on-line HPLC-DPPH assay. A negative peak at $517 \mathrm{~nm}$ corresponds to DPPH quenching, indicating an active compound. The UV absorbance spectrum of the major constituent is shown as inset $A$.

\section{Acknowledgements}

Many thanks is given to those who have generously aided this project by allowing us to collect fruit: Larry Schokman, Director of The Kampong; Chris Rollins, Director of the Fruit and Spice Park; Dr. Jonathan H. Crane of the University of Florida Tropical Research and Education Center; and the Broward County Rare Fruit and Vegetable Council.

\section{Literature Cited}

Anonymous. 1952. The Wealth of India, Vol X, pp 93-107. Council of Scientific and Industrial Research, New Delhi.

Bandoni, A.L., M.E. Mendiondo, R.V.D. Rondina \& J.D. Coussio. 1972. Survey of Argentine medicinal plants. I. Folklore and phytochemical screening. Lloydia 35:69-80.

Bate-Smith, E.C. 1963. Usefulness of chemistry in plant taxonomy as illustrated by the flavonoid constituents. Pp. 127140 in Chemical Plant Taxonomy. Edited by T. Swain. Academic Press, London.

Blumenthal, R.D., W. Lew, A. Reising, D. Soyne, L. Osorio, Z. Ying \& D. Goldenberg. 2000. Antioxidant vitamins reduce normal tissue toxicity induced by radio-immunotherapy. International Journal of Cancer 86:276-280.

Burns, J., P. Gardner, J. O'Neil, S. Crawford, I. Morecroft, D.B. McPhail, C. Lister, D. Matthews, M.R. MacLean, M.E.J. Lean, G.G. Duthie \& A. Crozier. 2000. Relationship among antioxidant activity, vasodilation capacity, and phenolic content of red wines. Journal of Agricultural Food Chemistry 48:220-230.
Cao, G., S.L. Booth, J.A. Sadowski \& R. Prior. 1998. Increases in human plasma antioxidant capacity after consumption of controlled diets high in fruits and vegetables. American Journal of Clinical Nutrition 68:1081-1087.

Cao, G., E. Sofic \& R. Prior. 1997. Antioxidant and prooxidant behavior of flavonoids: structure-activity relationships. Free Radical Biology and Medicine 22:749-760.

Consolini, A.E., O.A. Baldini \& A.G. Amat. 1999. Pharmacological basis for the empirical use of Eugenia uniflora L. (Myrtaceae) as antihypertesive. Journal of Ethnopharmacology 66:33-39.

Constant, H.L., K. Slowing, J.G. Graham, J.M. Pezzuto, G.A. Cordell \& C.W. Beecher. 1997. A general method for the dereplication of flavonoid glycosides utilizing high performance liquid chromatography/mass spectrometric analysis. Phytochemical Analysis 8:176-180.

Dewick, P. 1997. Medicinal Natural Products: A Biosynthetic Approach. John Wiley \& Sons, New York.

Duke, J. 2000. Chemicals in Eugenia uniflora. In Dr. Duke's Phytochemical and Ethnobotanical Databases: Agricultural Research Service, USDA, http://www.ars-grin.gov/duke.

Facciola, S. 1998. Cornucopia II. Kampong Publications, Vista, California.

Ferro, E., A. Schinini, M. Maldonado, J. Rosner \& G.S. Hirschman. 1988. Eugenia uniflora leaf extract and lipid me- 
tabolism in Cebus apella monkeys. Journal of Ethnopharmacology 24:321-325.

Formica, J.V. \& W. Regelson. 1995. Review of the biology of quercetin and related bioflavonoids. Food and Chemical Toxicology 33:1061-1080.

Franco, M.R.B. \& T. Shibamoto. 2000. Volatile composition of some Brazilian Fruits: Umbu-caja (Spondias cithereal), camu-camu (Myrciaria dubia), araca-boi (Theobroma grandiflorum). Journal of Agricultural Food Chemistry 48:12631265.

Frankel, E.N., J. Kanner, J.B. German, E. Parks \& J.E. Kinsella. 1993a. Inhibition of oxidation of human low-density lipoprotein by phenolic substances in red wine. The Lancet 341:454-457.

Frankel, E.N., A.L. Waterhouse \& J.E. Kinsella. 1993b. Inhibition of human LDL oxidation by resveratrol. The Lancet 341:1103-1104.

Gibbs, R.D. 1993. History of Chemical Taxonomy. Pp. 41-88 in Chemical Plant Taxonomy. Edited by T. Swain. Academic Press, London.

Giugliano, D. 2000. Dietary antioxidants for cardiovascular prevention. Nutrition, Metabolism and Cardiovascular Disease 10:38-44.

Haegele, A.D., C. Gillette, C. O’Neill, P. Wolfe, J. Heimedinger, S. Sedlacek \& H.J. Thompson. 2000. Plasma xanthophyll carotenoids correlate inversely with indices of oxidative DNA damage and lipid peroxidation. Cancer Epidemiology, Biomarkers and Prevention 9:421-425.

Harborne, J.B. 1963. Distribution of anthocyanins in higher plants. Pp. 359-388 in Chemical Plant Taxonomy. Edited by T. Swain. Academic Press, London.

Harborne, J.B. \& H. Baxter. 1999. Pages ix-xv, 30, 36, 39, 381, 384, 476 in The Handbook of Natural Flavonoids, Vol 2. John Wiley and Sons, New York.

Haron, N.W., D.M. Moore \& J.B. Harborne. 1992. Distribution and taxonomic significance of flavonoids in the genus Eugenia (Myrtaceae). Biochemical Systematics and Ecology 20:226-268.

Hegnauer, R. 1990. Chemotaxonomie der Pflanzen, Vol. 9:119-129. Birkhäuser Verlag, Berlin.

Hertog, M.G.L., E.J.M. Feskens, P. Hollman, M.B. Katan \& D. Kromhout. 1993. Dietary antioxidant flavonoids and risk of coronary heart disease: the Zutphen elderly study. The Lancet 342:1007-1011.
Hertog, M.G.L., D. Kromhout, C. Aravanis, H. Blackburn, R. Buzina, F. Fidanza, S. Glampaoli, A. Jansen, A. Menotti, S. Nedeljkovic, M. Pekkainen, B.S. Simic, H. Toshima, E.J.M. Fesens, P.C.H. Hollman \& M.B. Katan. 1995. Flavonoid intake and long-term risk of coronary heart disease and cancer in the seven countries study. Archives of Internal Medicine $55: 381-386$.

Hollman, P.C. \& M.B. Katan. 1999. Dietary flavonoids: intake, health effects and bioavailability. Food and Chemical Toxicology 37:937-942.

Jacob, R.A. \& B.J. Burri. 1996. Oxidative damage and defense. American Journal of Clinical Nutrition 63:985S-990S.

Kähkönen, M., A. Hopia, H. Vuorela, J. Rauha, K. Pihlaja, T. Kujala \& M. Heinonen. 1999. Antioxidant activity of plant extracts containing phenolic compounds. Journal of Agricultural Food Chemistry 47:3954-3962.

Kirtikar, K.R. \& B.D. Basu. 1988. Indian Medicinal Plants, Vol. 2:1038-1063. International Book Distributors, Dehradun.

Knekt, P., R. Järvinen, A. Reunanen \& J. Maatela. 1996. Flavonoid intake and coronary mortality in Finland: a cohort study. British Journal of Medicine 312:478-481.

Koleva, I.I., H.A.G. Niederlander \& T.A. van Beck. 2000. An on-line HPLC method for detection of radical scavenging compounds in complex mixtures. Analytical Chemistry 72:2323-2328

Landrum, L.R. 1988. The Myrtle family (Myrtaceae) in Chile. Proceedings of the California Academy of Science. 1988:277317.

Lee, M.-H., S. Nishinoto, L.-L. Yang, K.-Y. Yen, T. Hatano, T. Yoshida \& T. Okuda. 1997. Two macrocyclic hydrolysable tannin dimers from Eugenia uniflora. Phytochemistry 44:1343-1349.

Mabberley, D.J. 1993. The Plant Book. Bath Press, Avon.

McVaugh, R. 1966. Tropical American Myrtaceae: notes on generic concepts and descriptions of previously unrecognized species. Fieldiana: Botany 29:145-228.

Middleton, E. \& S. Kandaswami. 1993. The impact of plant flavonoids on mammalian biology: implictions for immunity, inflammation and cancer. Pp. 619-652 in The Flavonoids: Advances in Research Since 1986. Edited by J.B. Harborne. Chapman and Hall, London.

Morton, J. 1987. Fruits of Warm Climates. Julia Morton, Winterville, North Carolina. 
Nair, A.G.R. \& S.S. Subramanian. 1962. Chemical examination of the flowers of Eugenia jambolana. Journal of Science and Industrial Research 21B:457-458.

Ness, A.R. \& J.W. Powles. 1999. The role of diet, fruit and vegetables and antioxidants in the aetiology of stroke. Journal of Cardiovascular Risk 6:229-234.

Pellegrini, N., P. Riso \& M. Porrinni. 2000. Tomato consumption does not affect the total antioxidant capacity of plasma. Nutrition 16:268-271.

Pierpoint, W.S. 1986. Flavonoids in the human diet. Pp. 125-140 in Plant Flavonoids in Biology and Medicine: Biochemistry, Pharmacology, and Structure-Activity Relationship. Edited by V. Cody, E. Middleton \& J.B. Harborne. Alan R Liss, New York.

Pietta, P.-G. 2000. Flavonoids as antioxidants. Journal of Natural Products 63:1035-1042.

Popenoe, W. 1920. Manual of Tropical and Subtropical Fruits. Hafner Press, New York.

Rice-Evans, C., N. Miller \& G. Paganga. 1996. Structureantioxidant activity relationships of flavonoids and phenolic compounds. Free Radical Biology and Medicine 20:933-956.

Rice-Evans, C.A., N.J. Miller \& G. Paganga. 1997. Antioxidant properties of phenolic compounds. Trends in Plant Science 2:152-159.

Rivera, D. \& C. Obón. 1995. The ethnopharmacology of Madeira and Porto Santo islands, a review. Journal of Ethnopharmacology 46:73-93.

Robinson, T. 1991. The Organic Constituents of Higher Plants. Cordu Press, North Amherst.

Rücker, G., G.A.A.B. Silva, L. Bauer \& M. Schikarski. 1977. New constituents of Stenocalyx michelii. Planta Medica 31:322.

Schapoval, E.E., S.M. Silveira, M.L. Miranda, C.B. Alice \& A.T. Henriques. 1994. Evaluation of some pharmacological activities of Eugenia uniflora L. Journal of Ethnopharmacology 44:137-142.

Scheen, A.J. 2000. Antioxidant vitamins in the prevention of cardiovascular disease. Second part: results of clinical trials. Revue Medicale de Liege 55:105-109.

Schmeda-Hirschmann, G., C. Theoduloz, L. Franco, E. Ferro \& A. Rojas De Arias. 1987. Preliminary pharmacological studies on Eugenia uniflora leaves: xanthine oxidase inhibitory activity. Journal of Ethnopharmacology 21:183-186.
Silva, C.T.C. 1997. Postharvest modifications in camucamu fruit (Myrciaria dubia McVaugh) in response to stage of maturation and modified atmosphere. Pp. 23-26 in International Symposium on Myrtaceae; International Society for Horticultural Sciences. Curitiba, Brazil.

Slowing, K., E. Carretero \& A. Villar. 1996. Anti-inflammatory compounds of Eugenia jambos. Phytotherapy Research 10:S126-S127.

Slowing, K., M. Sollhuber, E. Carretero \& A. Villar. 1994. Flavonoid glycosides from Eugenia jambos. Phytochemistry 37:255-258.

Steinberg, D. 1997. A critical look at the evidence for the oxidation of LDL in atherogenesis. Atherosclerosis 131(Suppl.):S5-S7.

Theoduloz, C., L. Franco, E. Ferro \& G. SchmedaHirschman. 1988. Xanthine oxidase inhibitory activity of Paraguayan Mytraceae. Journal of Ethnopharmacology 24:179-183.

van Poppel, G., A. Kardinaal, H. Princen \& F.J. Kok. 1994. Antioxidants and coronary heart disease. Annals of Medicine 26:429-434.

Vinson, J., J. Jang, J. Yang, Y. Dabbagh, X. Liang, M. Serry, J. Proch \& S. Cai. 1999a. Vitamins and especially flavonoids in common beverages are powerful in vitro antioxidants which enrich low density lipoproteins and increase their oxidative resistance after ex vivo spiking in human plasma. Journal of Agricultural Food Chemistry 47:2502-2504.

Vinson, J., J. Proch \& L. Zubik. 1999b. Phenol antioxidant quantity and quality in foods: cocoa, dark chocolate, and milk chocolate. Journal of Agricultural Food Chemistry 47:4821-4824.

Wang, H., G. Cao \& R. Prior. 1997. Oxygen radical absorbing capacity of anthocyanins. Journal of Agricultural Food Chemistry 45:304-309.

Weyerstahl, P., H. Marschall-Weyerstahl, C. Christiansen, B.O. Oguntimein \& A.O. Adeoye. 1988. Volatile constituents of Eugenia uniflora leaf oil. Planta Medica 54:546549 .

Yamaguchi, T., H. Takamura, T. Matoba \& J. Terao. 1998. HPLC method for evaluation of the free radical-scavenging activity of foods by using 1,1-diphenyl-2-picrylhydrazyl. Bioscience, Biotechnology and Biochemistry 62:12011204.

Yoshikawa, M., H. Shimada, N. Nishida, Y. Li, I. Togauchida, J. Yamahara \& H. Matsuda. 1998. Antidiabetic principles of natural medicines. II. Aldose reductase and a- 


\section{Reynertson et al. - Antioxidant Potential of Seven Myrtaceous Fruits}

glucosidase inhibitors from Brazilian natural medicine, the leaves of Myrcia multiflora DC. (Myrtaceae): Structures of myrciacitrins I and II and myrciaphenones A and B. Chemical and Pharmaceutical Bulletin 46:113-119. 
